\title{
Effects of Septoplasty on Nasal Mucociliary Clearance in Patients Suffering from the Deviated Nasal Septum
}

\author{
Anuj K Goel
}

\begin{abstract}
Effect of deviated nasal septum and after its correction on nasal mucociliary clearance (NMC) values which was measured preoperatively and postoperatively using Anderson's method, was observed. Mucociliary clearance time in 20 patients suffering from deviated nasal septum was studied preoperatively and 2 months postoperatively. In the preoperative period, NMC values were significantly higher than the values measured after septoplasty. The NMC values of the control group and the NMC values of patients after septoplasty were not found different significantly. This study shows that deviated nasal septum affects NMC values which improve after septoplasty.
\end{abstract}

Keywords: Nasal mucociliary clearance, Nasal septum, Mucus.

How to cite this article: Goel AK. Effects of Septoplasty on Nasal Mucociliary Clearance in Patients Suffering from the Deviated Nasal Septum. Clin Rhinol An Int J 2018;11(1):18-20.

Source of support: Nil

Conflict of interest: None

\section{INTRODUCTION}

The nasal septum supports the external nasal framework and effects on airflow patterns in the nose. ${ }^{1}$ The septum also helps in proper humidification and temperature control of the inspired air and also helps in filtration of inspired air from particles by virtue of the ciliated nasal mucosa over it. ${ }^{2,3}$

Nasal mucociliary clearance is a primary physiological defense mechanism of upper as well as lower respiratory tract and thus maintains the state of health of the respiratory tract. The vital part of this mechanism is an adequate quantity of mucus with appropriate rhinological qualities and adequate functioning of cilia, which beat in a metachronous manner towards nasopharynx which ultimately either coughed out or swallowed. ${ }^{4}$ Defects in this process, either genetically or acquired,make an individual prone to get affected by chronic nasal,paranasal sinuses and airway tracts chronic infections. ${ }^{5}$

Associate Professor

Department of ENT, Saraswathi Institute of Medical Sciences, Hapur, Uttar Pradesh, India

Corresponding Author: Anuj K Goel, Associate Professor, Department of ENT, Saraswathi Institute of Medical Sciences, Hapur, Uttar Pradesh, India, e-mail: dranujgoel12@gmail.com
Deviated nasal septum effects over nasal functioning by changing airflow patterns and impairing NMC. It occurs due to increased mucus production, alteration in ciliary beating pattern. To correct the anatomical deformity of the nasal septum, the septoplasty procedure is performed widely in otorhinolaryngology. The aim of this study was to see the effects of nasal septum deviation over NMC values and post-septoplasty improvement in NMC values (using Andersen's saccharine method).

\section{MATERIALS AND METHODS}

We studied 20 patients with the deviated nasal septum (16 males and 4 females) between 18 and 31 years of age (mean 24 years), and 20 controls (17 males, 3 females), between age group of 18 and 27 years (mean 22 years). MCC was measured using Andersen's saccharine method in both cases and controls. Cases underwent MCC time measurement preoperatively and 2 months postoperative septoplasty. Approximately, a one-millimeter particle of commercially available saccharine was used for the test. The particle of saccharine was carefully placed on the floor of the nasal cavity about $1 \mathrm{~cm}$ behind the anterior end of the inferior turbinate. The patients were asked not to sniff, sneeze, eat, or drink during the test and to avoid deep breathing. They were asked to swallow every 30 seconds and to report the first change in their sensation of taste. The test was repeated in the other nostril and the mean of the two sides was taken as MCC time. This was done to exclude the effect if any, of the nasal cycle on MCC time. The results were statistically analyzed using students " $\mathrm{t}$ " test. Before each test; detailed history was obtained and routine ear, nose and throat examination was carried out. The diseases which are known to affect NMC like nasal polyps, foreign bodies nose, enlarged adenoids, allergic and atrophic rhinitis along with lower airway obstructive conditions like bronchial asthma and chronic pulmonary diseases were excluded from the study.

Correction in deviated septum was done by performing septoplasty using local anesthesia. Fifteen minutes before surgery, the nasal cavity was lightly packed with cotton wool nasal packs soaked in xylocaine $(4 \%)$ and adrenaline $(1: 100,000)$. After freer's incision mucoperichondrialperiosteal flap is elevated and the deformity of the nasal 
septum was corrected. After that anterior nasal packing was done which was removed 48 hours postoperatively. Differences with a $p$ value less than 0.05 were accepted as significant.

\section{RESULTS}

Preoperatively and 2 months postoperatively NMC was measured. No significant difference was found in for any of the deviated nasal septum (DNS) types $(p>0.05)$. Preoperative and postoperative mucociliary clearance time was obtained in 20 patients and 20 controls. Before the septoplasty, mean \pm SD MCC time in patients was 16.52 +8.06 min on the concave side while $12.36+4.83$ on the convex side. After two months of surgery, MCC time was $11.88+4.33 \mathrm{~min}$ on the concave side while $11.66+3.53$ min on the convex side. In controls, MCC time was 11.36 +4.33 on the right side while $11.06+3.53$ min on the left side (Table 1). The mean MCC time of the concave side of DNS patients was significantly longer than of the convex side $(p<0.05)$ and no significant difference was noted in MCC in both sides of the nasal cavity in control group. The MCC time in the convex side of patients with DNS showed no significant difference with those of the right and left the side of nasal cavities of the control group $(p>0.05)$ (Table 1). MCC time of concave side in patients with DNS showed a significant difference before and after two months of septoplasty $(p<0.05)$.

\section{DISCUSSION}

Mucociliary transport is the physiological process in which the mucous layer on the mucosa is moved by the ciliated cells. Mucociliary clearance in nose depends on the number of cilia, the beat frequency, their coordinated movements, the amount of nasal fluid and viscoelastic properties. ${ }^{6}$ Defective mucociliary clearance can be due to abnormalities in the ciliary (number or beating pattern) or mucous components or a combination of both. ${ }^{7}$ The

Table 1: Mean + SD mucociliary clearance time in bilateral nasal mucosa of patients with deviated nasal septum (DNS) and control subjects

\begin{tabular}{llll}
\hline $\begin{array}{l}\text { Patient } \\
\text { group }\end{array}$ & Nasal cavity & $\begin{array}{l}\text { Mean MCC } \\
\text { time }(\text { min })\end{array}$ \\
\hline DNS $(n=20)$ & $\begin{array}{l}\text { Preop } \\
\text { Preop }\end{array}$ & $\begin{array}{l}\text { Concave side } \\
\text { Convex side }\end{array}$ & $16.52+8.06$ \\
& $\begin{array}{l}\text { 2 months } \\
\text { postop }\end{array}$ & Concave side & $11.88+4.36$ \\
& $\begin{array}{l}\text { 2 months } \\
\text { postop }\end{array}$ & Convex side & $11.66+3.53$ \\
& & Right side & $11.36+4.33$ \\
$\begin{array}{l}\text { Control } \\
(n=20)\end{array}$ & & Left side & $11.06+3.53$ \\
\hline
\end{tabular}

anatomical structure and physiological properties of the nose are remarkable in maintaining a fairly constant environment for the mucociliary system to function at its best, although nasal mucociliary clearance is fairly constant, it may vary with the place, habit, habitat, climate, race, and temperature. So, it is advisable that individual laboratory establish it's own normal value of nasal mucociliary clearance. DNS affects nasal mucociliary clearance negatively by decreasing cilia in numbers, increasing inflammation and decreasing the density of glandular acini. After septoplasty mucociliary clearance improves with time. There are several studies which show that septoplasty improves the nasal mucociliary clearance significantly. $8,9,10,11$ Methods to evaluate the nasal mucociliary clearance include direct observation of dyes or particles deposited on the nasal mucosa, ${ }^{12}$ use of radioactive microdroplets, single radioactively tagged resin particles ${ }^{13}$ and radiopaque teflon discs monitored by external device. ${ }^{13}$ Andersen et al. described a very simple, quick, noninvasive and serves as a valuable screening test. ${ }^{13}$ Klingbeil et al. studied the results of the saccharine test in the pediatric bronchopulmonary outpatient department and found that in 381 children of age 3-17 years the average nasomucociliary clearance time was $6.6( \pm 4.8)$ minutes in healthy controls. ${ }^{14}$ Our study showed that deviated nasal septum impairs the nasal mucociliary clearance. However, to understand if there is real statistically significant difference between NMC rate values newer studies with large sample size should be performed.

\section{REFERENCES}

1. William EW, Robertt CK. Sinonasalanatomy, function and evaluation.In: Bailey BJ, Johnson JT, Newsland SD (eds) Head and neck surgery-otolaryngology, 4 th edn. Lippincott Williams \& Wilkins, Philadelphia, 2006; pp 307-318.

2. Simmen D, Scherrer JL, Moe K, et al. A dynamic and direct visualization model for the study of nasal airflow. Arch Otolaryngol Head Neck Surg 1999;125:1015-1021.

3. Toremalm NG. Aerodynamics and mucociliary function of upper airways. Eur J Respir Dis Suppl 1985;139:54-56.

4. Reynolds HY.Respiratory host defences-Surface immunity original research article.Immunobiology 1994;191:402-412.

5. Sato S, Kinoyo H. The mucosal immune system of the respiratory tract.Current Opinion in Virology 2012;2:225-232.

6. Passali D, Ferri L, Becchini G, et al. Alterations of nasal mucociliary transport in patients with hypertrophy of the inferior turbinates, deviations of the nasal septum and chronic sinusitis.Eur Arch Otorhinolaryngol 1999;256:335-337.

7. Awotedu AA, Babalola OO, Lawani EO, et al. Abnormalmucociliary action in asthma and bronchiectasis. Afr J Med Sci 1990;19(3):153-156.

8. Uslu H, Uslu C, Varoglu E, et al. Effects of septoplasty and septal deviation on nasal mucociliary clearance. Int J Clin Pract 2004;58:1108-1111. 
9. Jang YC, Myong NH, Park KH, et al.. Mucociliary transport and histologic characterstics of the mucosa of deviated nasal septum.ArchOtolaryngol Head Neck Surg 2002;128:421-424.

10. Ulusoy B, Arbag H, Sari O, et al. Evaluation of the effects of nasal septal deviation and its surgery on nasal mucociliary clearance in both nasal cavities. Am J Rhinol 2007;21:180-183.

11. Brondeel L, Sonstabo R, Clement P et al. Value of Tc-99m particle test, the saccharine test in mucociliary examinations. Rhinology 1983;21:135.
12. Ewort G. On the mucus rate in human nose. Acta Otolaryngol Suppl 1965;(Suppl 200):1-62.

13. Anderson I, Lundqvist G, Jonson PL, et al. Nasal clearance in monozygotic twins. Am Rev respire Dis 1974;110(3):301-305.

14. Klingbeil P, Wiersbitzky S, Bruns R, et al. The saccharine test in the pediatric broncho-pulmonologic outpatient clinic. A noninvasive screening method for the assessment of ciliary function of the respiratory tract in children. Kinderarztl Prax 1990;58(4):205-210. 